scientific knowledge, the change in sexual attitudes has resulted from a wide variety of factors: changes in kinship and family system; economic, social and political changes; and the changing form of social regulations (Weeks, 1981).

India is still a largely non-permissive society where ignorance about sexual matters is widely prevalent. A large majority of the population does not receive any kind of sex education, and discussing sexuality openly is a taboo. Ignorance thus breeds more ignorance, with quacks and self-appointed 'sexologists' perpetuating erroneous views, just as happened in the West earlier. Dhat syndrome thus appears to be a variation of the centuries-old false beliefs and ignorance. It is 'culture-bound' only in the sense that it represents the immense 'cultural' difference between the scientifically aware medical population and the myth-orientated native population.

DANGerfield, G. N. (1843) The symptoms, pathology, causes and treatment of spermatorrhoea. Lancet, $i, 211-216$.

Foucault, M. (1979) The History of Sexuality, Vol. I. London: Allen Lane.

Haller, J. S. \& Haller, R. M. (1974) The Physician and Sexuality

in Victorian America. Chicago: University of Illinois Press. TaNNAHILl, R. (1980) Sex in History. London: Hamish Hamilton. WeEks, J. (1981) Sex, Politics and Society. London: Longman.

Department of Psychiatry

SWARAN P. SingH

Queen's Medical Centre

Nottingham NG7 $2 \mathrm{UH}$

\section{Stability of negative symptoms of schizophrenia}

SIR: Ring and colleagues (Journal, October 1991, 159, 495-499) reported the negative association between the illness variables and negative symptoms in schizophrenia and the stability of negative symptoms.

The negative symptoms in the 20 long-stay chronic schizophrenic patients reported by Mathai \& Gopinath (1986) were reassessed by the same investigators after a period of two and a half years. The sample included 17 females and 3 males. The mean age was 42.35 years (s.d. 9.34) at the time of the initial assessment. The mean durations of illness and hospital admission were 16.84 years (s.d. 5.95) and 13.94 years (s.d. 7.20) respectively. The variables believed to affect negative symptoms, i.e. the wards the patients were admitted to, the occupational therapy units where they worked, the amount of activity, social stimulation, and medications, were maintained the same as at the initial assessment. The negative symptoms were assessed using the SANS
(Andreasen, 1981) based on direct observation and interview, and nurses' and occupational therapists' reports. Except for a significant $(P<0.001)$ increase in attentional impairment in $15 \%$ of the patients, the scores in all subscales and the total scores remained stable. Our findings were comparable to those of Ring $e t$ al, i.e. in general the negative symptoms were stable over time and neither the initial scores nor the change at the reassessment could be correlated to any demographic, clinical or treatment variable. It is interesting to note that this study was conducted in a patient population different in ethnic, demographic and clinical characteristics, over an extended period of 30 months.

ANDREASEN, N. C. (1981) Scale for Assessment of Negative Symptoms (SANS). Iowa City: University of Iowa.

Mathal, P. J. \& Gopinath, P. S. (1986) Deficits of chronic schizophrenia in relation to long term hospitalisation. British Journal of Psychiatry, 148, 509-516.

St Fintan's Hospital

Albert Michael

Portlaoise, Co. Laois

Republic of Ireland

P. John Mathal

Medical College, Kottayam

India, 686008

Santosh K. Chaturvedi

P. S. GOPINATH

NIMHANS, Bangalore

India, 560029

\section{Problem drinking in women}

SIR: The rise in female admissions for alcohol problems to psychiatric hospitals is disproportionate to the number of male admissions although men comprise the majority of such referrals (Madden, 1984). We were thus surprised when we noticed more female than male referrals to our hospital. In order to gain a better understanding of this, we undertook a study to identify differences between men and women being referred.

Our hospital keeps a case register listing in-patient admissions and their diagnosis by ICD-9 criteria. Patients eligible for our study had been admitted between January 1987 and December 1989, and ascribed an ICD-9 diagnosis of alcohol dependency syndrome (303.0). All patients came from the catchment area of a general psychiatric hospital in Birmingham.

Our study is a retrospective case note review of patients meeting the inclusion criteria. Of 19 patients who fulfilled this, 11 were women (mean (s.d.) 
age $=41.6(10.1)$ years), and eight men (mean (s.d.) age $=46.3(9.4)$ years). Three women were divorced and the other eight married, contrasting with two married men, one separated man and four single, i.e. never married, men, among the seven for whom this data was recorded.

The mean (s.d.) age of the onset of drinking was 21.8 (7.6) years for the women compared with 17.8 (2.7) years in the men. Men had drunk for 26.7 (10.2) years before seeking treatment compared with 18.0 (7.2) years in women. Of the women, eight had suffered from medical complications, compared with only three of the men. Women were more likely to drink at home on their own than men $(81.8 \%$ compared with $42.9 \%$ ).

While numbers in our sample were too small to allow a statistical analysis, these results agree with earlier studies (e.g. Leyland, 1982; Schmidt et al, 1990 ) in suggesting that women present to psychiatric services at a similar age to men but with a shorter history of drinking. They are more prone to the medical sequelae of heavy drinking and more likely to drink alone.

We were surprised to find women in our sample drank more heavily than the men, drinking on average 23.7 (14.9) units of alcohol per day compared with 18.0 (7.0) units in the men, contrary to work suggesting that male problem drinkers are the heaviest drinkers (Schmidt et al, 1990). We were also interested to note that of eight married women only two reported marital problems. Both the married men felt their marriage was in jeopardy and thus no males had a stable relationship, although factors other than alcoholism might have accounted for the low relationship rate in the men.

This study reminds us of several facts. Firstly, the number of females referred for help with alcoholrelated problems is increasing disproportionately with respect to male referrals. Secondly, women drinkers often have specific problems needing to be addressed which are less apparent or absent in male drinkers, for example, greater risk of stigmatisation or medical sequelae. Lastly, as many women drink at home, it may be less obvious that alcohol is a problem. It is notable that there is little work done on gender difference in alcohol problems and that only one voluntary agency has a designated service for female problem drinkers. We therefore feel it is important to draw this rising problem to the attention of the non-specialist general psychiatrist.

LEYLAND, J. (1982) Gender, drinking and alcohol abuse. In Gender and Psychopathology (ed. I. Al-Issa), pp. 201-220. New York: Academic Press.

MADDEN, J. S. (1984) A Guide to Alcohol and Drug Dependence. Bristol: Wright.
SChmidt, C.. KleE, L. \& Ames, G. (1990) Review and analysis of literatures on indicators of women's drinking problems. British Journal of Addiction. 85, 179-192.

S. D. SMITH

F. OYEBODE

The John Conolly Hospital

Bristol Road

South Rednal

Birmingham B45 9BD

\section{Cyproterone acetate therapy and aggression}

SIR: The recent correspondence from Thibaut et al (Journal, August 1991, 159, 298-299) on the potential benefits of cyproterone acetate therapy in aggression is both stimulating and a source of concern. Recent experience in our hospital has led to some doubts regarding the use of this medication, particularly with elderly patients. The following case history will demonstrate this point.

Case report. $\mathrm{Mr} \mathrm{X}$, a 70-year-old long-term patient in our hospital, had long been a problem due to his proclivity for fondling the female staff and female patients, at every available opportunity. This behaviour had defied numerous behavioural strategies designed to curb his activities. Staff frustration was understandable as numerous violent incidents had developed between $\mathrm{Mr} \mathrm{X}$ and other patients on the unit. A trial of cyproterone acetate, at a dose of $50 \mathrm{mg}$ twice daily, was commenced, and the patient's behaviour was observed.

Over a two-week period, $\mathrm{Mr} \mathrm{X}$ became progressively more inactive, and he tended to spend more time sitting in a chair - he had previously been very physically active. His attempts to fondle patients and staff did not diminish, however, as he would reach out and fondle any female in the vicinity. Over time we observed that $\mathrm{MrX}$ had become quite immobile, and he would fall from standing when staff helped him walk. He suffered several falls resulting in a number of minor injuries. Active mobilisation did not produce significant benefit. Marked atrophy of the quadriceps muscles was noted bilaterally. Cyproterone acetate therapy was discontinued after one month, and within two weeks, $\mathrm{Mr} \mathrm{X}$ was again fully mobile, and his behaviour was unchanged. His quadriceps muscles have increased almost two centimetres in circumference, and he has had no further falls.

Our experience with cyproterone acetate has not been a favourable one. Admittedly, our elderly patients are often treated for sexual aggression, but the responses we have observed are not favourable, with problems of a different nature developing. Our experience in the treatment of over a dozen cases of sexually aggressive males and females has led us to believe that cyproterone acetate therapy is fraught with difficulties. Certainly, there may be a role for this drug in selected cases of aggressive behaviour, 